\title{
Um panorama da pesquisa em operações sustentáveis
}

\author{
Pâmela Mocelin Manfrina, André Luiz Gazoli de Oliveirab ${ }^{\mathrm{b}}$, Silvia Marques Lima Chimanskic, \\ Edson Pinheiro de Lima ${ }^{\mathrm{d} *}$, Sérgio Eduardo Gouvêa da Costa ${ }^{\mathrm{e}}$ \\ apamela.manfrin@pucpr.br, PUCPR, Brasil \\ bandre.gazoli@pucpr.br, PUCPR, Brasil \\ 'silvia.m.chimanski@hsbc.com.br, Instituto HSBC Solidariedade, Brasil \\ d*e.pinheiro@pucpr.br, PUCPR/UTFPR, Brasil \\ 's.gouvea@pucpr.br, PUCPR/UTFPR, Brasil
}

\begin{abstract}
Resumo
É notável o progresso da humanidade no último século. A grande questão que se apresenta na atualidade é até quando os recursos naturais serão suficientes para atender a crescente demanda imposta pelos atuais modelos de produção. 0 presente artigo visa reunir informações que fundamentem a gênese de um novo modelo de produção, concebido a partir de uma nova agenda mundial em que a sustentabilidade ocupa uma posição central. Este estudo está delimitado por uma definição de sustentabilidade a partir de visões econômicas, meio ambientais e sociais, bem como na interseção entre as áreas de desenvolvimento sustentável e gestão de operações. A pesquisa realizada é de natureza bibliográfica, fundamentada nas bases de dados que compõem o portal de periódicos da Capes e em técnicas de análise de redes sociais. As redes sociais identificam relacionamentos em termos de palavras-chave e autores, e análises descritivas dos artigos levantados complementam o estudo do que se têm publicado em temas relacionados à sustentabilidade na área de gestão de operações.
\end{abstract}

Palavras-chave

Gestão de operações. Gestão estratégica de operações. Operações sustentáveis. Sustentabilidade.

\section{Introdução}

A sustentabilidade é um tema emergente abordado em diversas áreas do conhecimento. Ao realizar uma pesquisa rápida em bases de dados multidisciplinares é possivel identificar que esse tema é citado em áreas como: ciências da terra e meio ambiente; humanidades, ciências sociais e direito; ciências biomédicas e ciências da vida; economia e negócios; e engenharia. Esse fato expõe a relevância do tema no cenário acadêmico mundial (COORDENAÇÃO..., 2010).

Sachs (2004) salienta que a sustentabilidade depende da capacidade de uma civilização de se ater aos princípios da prudência ecológica e do uso eficiente da natureza, gerando assim uma forma de desenvolvimento sustentável. 0 autor também destaca que a problemática de desenvolvimento sustentável passou de seu status de modismo para assumir importância acadêmica. Nesse contexto, o desenvolvimento sustentável é um conceito importante que influenciará as características dos negócios e das indústrias no século XXI.

0 termo desenvolvimento sustentável foi utilizado pela primeira vez em 1987 no documento da ONU conhecido como Relatório Brundtland. Esse relatório estabeleceu que o conceito de desenvolvimento sustentável objetiva atender as atuais necessidades de recursos para o progresso técnico e econômico, preocupando-se com a capacidade de as gerações futuras também satisfazerem as suas necessidades (KRAJNC; GLAVIČ, 2005; WORLD..., 1987).

Existe uma discussão na literatura multidisciplinar sobre sustentabilidade que caracteriza o desenvolvimento sustentável como o anúncio de uma utopia que tomará o lugar do socialismo (VEIGA, 2006). 
Keinert (2008) destaca que o termo sustentável abrange também a esfera organizacional. Por conseguinte, implica no desenvolvimento de modelos que consideram a sustentabilidade. Há, portanto, um crescente uso de indicadores de desempenho socioambientais que visam o desenvolvimento de estratégias fundamentadas na sustentabilidade das operações. Contudo, apesar de a maioria das empresas incorporar em seu discurso o conceito de sustentabilidade, não se observa uma substancial mudança da prática em seus processos produtivos. As políticas de desenvolvimento econômico e industrial brasileiras não conduzem ao desenvolvimento de um modelo fundamentado na sustentabilidade.

Modelos de sustentabilidade vêm sendo construídos tendo como referência o Triple Bottom Line - 3BL, cobrindo os três aspectos que definem a sustentabilidade: impacto ambiental, responsabilidade social e contribuição econômica. Considera-se que muitas empresas já estão engajadas em atividades de desenvolvimento sustentável, ações caracterizadas pela produção de bens e serviços por meio de processos e sistemas não-poluentes, que conservam energia e recursos naturais economicamente viáveis, desenvolvidos e entregues de forma segura e saudável a todos os colaboradores, comunidades e consumidores, de forma criativa e socialmente gratificante para todos os stakeholders (KRAJNC; GLAVIČ, 2005; VELEVA; ELLENBECKER, 2001).

Até o momento, muitas empresas utilizam apenas indicadores econômicos para medir a eficácia de seus negócios. Apesar disso, existem diversos acordos e contratos tendo como origem a demanda dos clientes que exigem relatórios que incluam informações sobre sustentabilidade. Diante disso, os relatórios empresariais estão incluindo essa perspectiva e assim integrando informações econômicas, ambientais e sociais (GLOBAL..., 2002).

Krajnc e Glavič (2005) identificam a ocorrência de importantes desenvolvimentos no que se refere à formulação de relatórios de sustentabilidade. Dentre esses progressos destacam-se as informações e orientações fornecidas pelo World Business Council for Sustainable Development (WORLD..., 1997), do Global Reporting Initiative (GLOBAL..., 2002) e o desenvolvimento de padrões para sistemas de gestão ambiental como as normas ISO 14000 e EMAS (ORGANIZATION..., 2001). Além disso, os autores comentam que, embora a existência de frameworks abordando esses indicadores, eles não constituem medida do desempenho das organizações.

Diante da característica multidisciplinar da sustentabilidade, que culmina em diversas abordagens e temas de estudo, o presente trabalho objetiva realizar um estudo da literatura de sustentabilidade, fundamentado na análise de redes de relacionamento e delimitado pela área de gestão de operações. A pesquisa foi realizada tendo como referência publicações que constam nas bases de dados do portal de periódicos da Capes nos últimos 10 anos (2000 a 2010).

0 estudo apresenta inicialmente uma breve introdução aos principais conceitos de sustentabilidade para então desenvolver propriamente a análise da literatura. São identificados os principais autores e pesquisadores, os principais periódicos e os temas relevantes para a pesquisa de sustentabilidade em gestão de operações. A análise de redes de relacionamento permite identificar a relação dos indivíduos de forma simples e objetiva, resultando na construção de gráficos e tabelas de relacionamento. Um conjunto de indicadores complementa a análise de relacionamento, permitindo avaliar as redes no que se refere a: densidade, centralidade e ou centralização, proximidade e intermediação.

\section{Referencial teórico}

Conforme citado anteriormente, uma das definições utilizadas para sustentabilidade é atender às necessidades do presente sem comprometer a capacidade de as futuras gerações atenderem às suas próprias necessidades (WORLD..., 1987).

É possível desenvolver uma discussão acerca da sustentabilidade tendo como pano de fundo a contribuição das empresas, na medida em que suas ações se orientam para a criação de um desenvolvimento sustentável. Esse tema vem sendo discutido largamente na última década e muitas são as medidas adotadas para as empresas alcançarem padrões reconhecidos de sustentabilidade. Observando o conjunto das ações desenvolvidas, algumas delas sugerem que as empresas devem ter uma postura reativa ante o desenvolvimento sustentável, ou seja, suas respostas dependem de demandas de seus stakeholders e são avaliadas por modelos tradicionais de custo-benefício. Por outro lado, há ações definidas por uma postura pró-ativa, em que a proposição de valor é modificada para fundamentar-se nos pilares do 3BL (ARAS; AYBARS; KUTLU, 2010; UEDA et al., 2009; ARAS; CROWTHER, 2008; FIGGE; HAHN, 2004).

A sustentabilidade pode ser abordada em seus conceitos nos níveis macroeconômico e empresarial. Ao tratar a sustentabilidade em seu nível macroeconômico, o principal objetivo desses conceitos é aumentar, ou, no mínimo, estabilizar o bem-estar ou a utilidade ao longo do tempo, não comprometendo a capacidade de desenvolvimento das gerações futuras. Ao se tratar formalmente do tema nas discussões sobre desenvolvimento sustentável, os economistas 
frequentemente utilizam a abordagem da teoria do capital para definir sustentabilidade. Introduz-se, portanto, o conceito de substituição e determinam-se níveis de "susbstituibilidade" para o capital artificial, natural, humano e social. A sustentabilidade no nível empresarial é julgada de acordo com o desempenho organizacional em dimensões econômicas, ambientais e sociais. 0 grau de substituição de capital artificial, natural, humano e social também se aplica no nível empresarial. No extremo forte não são realizadas substituições e, sendo assim, é preciso ter um desempenho superior em determinada dimensão, mantendo as demais em padrões aceitáveis. Já no extremo fraco, em que há substituição de capital, são trabalhadas compensações para o mau desempenho em determinadas dimensões (SARKIS; HELMS; HERVANI, 2010; GLASER, 2006; FIGGE; HAHN, 2004; CABEZAS et al., 2003; NEUMAYER, 1999; HARTE, 1995; COSTANZA; DALY, 1992; PEARCE, 1988; HICKS, 1946).

0 3BL pode ser utilizado para definir as dimensões dos impactos gerados pelas empresas que participam de determinada indústria. A partir dessa perspectiva, o desempenho de uma organização é definido nos aspectos econômicos, sociais e ambientais. Esses três fatores devem necessariamente agir de forma integrada, proporcionando sustentabilidade para a organização e a sociedade na qual ela se insere. Não surpreendentemente, grandes empresas têm apresentado em seus relatórios corporativos indicadores que remetem ao desempenho não financeiro, dedicando parte de suas auditorias a fenômenos socioambientais (TATE; ELLRAM; KIRCHOFF, 2010; ANDRADE; GOSLING; XAVIER, 2010; ISAKSSON; STEIMLE, 2009; SIENA, 2008; ISAKSSON; GARGAVE, 2003; TÖPFER, 2000; ELKINGTON, 1999).

Procurando melhor definir os elementos que compõem o 3BL, os autores lsaksson e Gargave (2003) propuseram a mudança dos termos igualdade social ou responsabilidade social, comumente associados à dimensão social, para ética. Os autores acreditam que o termo "ético" descreve de forma mais clara os requisitos normalmente utilizados em responsabilidade social.

Uma pesquisa envolvendo gestão estratégica de operações e sustentabilidade promovida pelo Lowell Center for Sustainable Production da Universidade de Massachusetts desenvolveu um modelo de referência para que as empresas compreendam o conceito de produção sustentável e possam avaliar a eficácia de seus sistemas de indicadores de sustentabilidade. 0 modelo possui uma estrutura que consiste em cinco níveis para classificar os indicadores existentes em relação a princípios básicos de sustentabilidade estabelecidos em termos de: energia e uso de matérias-primas; meio ambiente; desenvolvimento local e justiça social; desenvolvimento econômico; força de trabalho; produtos e serviços (LOWELL CENTER, 2010; VELEVA; ELLENBECKER, 2001; VELEVA et al., 2001).

0 Quadro 1 apresenta os níveis do modelo Lowell Center for Sustainable Production - LCSP.

0 objetivo do modelo LCSP é fundamentar uma metodologia ou processo para avaliar a capacidade de um conjunto de indicadores contribuir para a tomada de decisão e o progresso em direção a sistemas de produção mais sustentáveis.

Um breve contexto a respeito de sustentabilidade e gestão estratégica de operações foi estabelecido e uma análise mais criteriosa do que se produziu cientificamente no tema foi feita para ajudar a compreender os desafios e problemas que podem pautar uma agenda de pesquisa.

\section{Desenvolvimento da pesquisa}

0 presente trabalho orienta-se a partir de um conjunto básico de conceitos relacionado à gestão estratégica de operações e sustentabilidade para desenvolver uma análise de citação e cocitação. 0 estudo é realizado utilizando a representação de redes de relacionamento, para se ter uma fotografia da pesquisa realizada nesse tema.

Segundo Wasserman e Faust (1994), a análise de redes de relacionamento possui sua origem em estudos da sociologia, da psicologia social e da antropologia. A relação entre grupos de pessoas, indivíduos ou entidades que trocam informações entre si é conhecida como rede de relacionamento. Breiger (2004) define os estudos fundamentados em redes de relacionamento como uma pesquisa disciplinada que permite modelar as relações entre os atores de um grupo social, bem como padronizar os relacionamentos entre esses atores em diferentes níveis de análise. Nesse mesmo contexto, Capra (2003) salienta que as redes de relacionamento desenvolvem processos de comunicação que envolvem aspectos como linguagem, cultura e relações de poder entre os indivíduos envolvidos.

Senge (2005) destaca que um grupo de indivíduos interligados via fluxo de informações na forma de redes gera um círculo causal de fatos. Esse grupo de indivíduos tem como característica ser alimentado por dados e informações interligadas entre si, ocasionando e projetando um impacto sobre as próximas variáveis do sistema. Dessa forma, as ações estão interconectadas, sendo possível simular a consequência da ação em um espaço de tempo, seja ele curto ou longo. 
Quadro 1. Modelo LCSP.

\begin{tabular}{|c|c|}
\hline Nível de avaliação & Descrição \\
\hline $\begin{array}{c}\text { Nível } 1 \text { - Conformidade das } \\
\text { instalações }\end{array}$ & $\begin{array}{l}\text { Avalia em que medida as instalações de uma empresa estão em conformidade com o marco regulatório } \\
\text { vigente, bem como com relação à padrões e recomendações do setor em que atua, quer seja definido pela } \\
\text { indústria ou pelo mercado servido. } \\
\text { Muitas empresas gerenciam indicadores do nível } 1 \text { que estão geralmente circunscritos às instalações da } \\
\text { própria empresa e constituem uma resposta da empresa a demandas externas. } \\
\text { Exemplos: total de efluentes e resíduos gerados e informados; número de notificações recebidas por não } \\
\text { conformidades. }\end{array}$ \\
\hline $\begin{array}{l}\text { Nível } 2 \text { - Desempenho no uso de } \\
\text { recursos }\end{array}$ & $\begin{array}{l}\text { Este nível compreende medidas relacionadas às operações ou ao processo produtivo, na forma de } \\
\text { entradas, saídas e desempenho. Envolve aspectos relacionados a uso eficiente e racional de recursos, } \\
\text { subprodutos, emissões de gases e resíduos. } \\
\text { Exemplos: toneladas de sedimentos gerados; toneladas de emissões de gases; total de kWh de energia } \\
\text { consumida por kg de produto produzido. }\end{array}$ \\
\hline $\begin{array}{l}\text { Nível } 3 \text { - Efeitos potenciais no } \\
\text { meio ambiente e na saúde }\end{array}$ & $\begin{array}{l}\text { Avalia o potencial efeito das instalações de uma empresa no meio ambiente e na saúde pública. } \\
\text { Exemplos: quantidade de emissão de gases de efeito estufa (greenhouse gas - GHG), medida anualmente } \\
\text { em equivalentes } \mathrm{CO}_{2} \text { (Global Warming Potential - GWP); quantidade de emissões de gases que afetam } \\
\text { a camada de ozônio, medida em equivalentes anuais de etileno (Photochemical Ozone Creating } \\
\text { Potential - POCP); quantidade de efluentes na forma de substâncias ácidas, medidas em equivalentes } \\
\text { anuais de } \mathrm{SO}_{2} \text { (Acidification Potential). }\end{array}$ \\
\hline $\begin{array}{l}\text { Nível } 4 \text { - Cadeia de suprimentos e } \\
\text { ciclo de vida do produto }\end{array}$ & $\begin{array}{l}\text { Neste nível, o escopo de análise se amplia para toda a cadeia de suprimentos e também abrange todo o } \\
\text { ciclo de vida do produto, envolvendo aspectos da sua distribuição, uso e destino final após a vida útil. } \\
\text { Neste nível podem ser usadas as mesmas medidas dos três níveis anteriores, no entanto o escopo se } \\
\text { amplia para fornecedores, distribuidores e usuários finais. No nível } 4 \text {, os indicadores de sustentabilidade } \\
\text { buscam avaliar o uso de matérias-primas de fontes renováveis e/ou reuso ou reciclagem de produtos no } \\
\text { final da sua vida útil. } \\
\text { Exemplos: percentagem de produtos projetados para serem reusados ou reciclados; percentagem anual de } \\
\text { fornecedores recebendo treinamento em saúde e segurança no trabalho; quantidade de energia associada } \\
\text { às principais matérias-primas e embalagens; toneladas de emissões GHG durante o transporte de produtos. }\end{array}$ \\
\hline Nível 5 - Sistemas sustentáveis & $\begin{array}{l}\text { Este nível mostra como um processo de produção de uma empresa se enquadra no modelo de sociedade } \\
\text { sustentável. A produção sustentável não é uma atividade isolada, ela está integrada aos sistemas } \\
\text { econômico, ambiental e social de uma comunidade. Nesse contexto, comunidade, encontram-se tanto o } \\
\text { contexto local onde as instalações estão localizadas como também o contexto global onde a organização } \\
\text { vende os seus produtos e serviços e se abastece de matéria-prima e equipamentos. } \\
\text { lndicadores no nível } 5 \text { avaliam os efeitos de longo prazo de um sistema de produção no que se refere a } \\
\text { qualidade de vida, desenvolvimento humano e capacidade de renovação do meio ambiente. Nesse senso, } \\
\text { as medidas do nível } 5 \text { avaliam o quanto os materiais e serviços do ecossistema usados pela empresa, ao } \\
\text { longo da sua cadeia de suprimentos e ciclo de vida do produto, estão sendo utilizados dentro de taxas } \\
\text { que permitam a sua renovação ou dentro da capacidade de assimilação da natureza. Trata-se de um nível } \\
\text { de avaliação que depende de referências estabelecidas pelas comunidades e governos. } \\
\text { Exemplos: percentual de água utilizada de fontes locais, considerando as taxas médias de recargas } \\
\text { hidráulicas; percentual do total de energia utilizada proveniente de fontes renováveis. }\end{array}$ \\
\hline
\end{tabular}

Fonte: Lowell Center (2010).

Segundo Alejandro e Norman (2006), uma rede é composta por vínculos, nós e fluxos. Cada elemento possui características próprias, que são:

- Nós: elementos da rede que se agrupam com um objetivo em comum;

- Vínculos: são os laços que existem entre dois ou mais nós. Os vínculos entre um nó e outro nó são representados por linhas; e

- Fluxos: indicam a direção do fluxo de informação, também indicada por uma linha e uma seta. Os fluxos podem ser unidirecionais quando a informação é destinada para um nó e bidirecionais quando o fluxo de informações é transmitido e recebido pelo mesmo elemento da rede.

Para realizar a construção e análise de redes de relacionamento utilizou-se o software UCINET $6.109^{\circledR}$. Por meio de grafos é construída uma visualização das relações e interligações. Não obstante, o software também apresenta indicadores para análise das redes de relacionamento baseados no cálculo de:

- Densidade: apresenta o grau de conectividade que o nó tem dentro da rede;

- Centralidade: medida do número de relações existentes entre elementos da rede;

- Centralização: nível de centralização que um elemento apresenta na rede, sendo uma medida da quantidade de informações direcionada para determinado elemento da rede;

- Intermediação: medida da quantidade de intermediações que um elemento exerce no fluxo de informações de uma rede; e

- Proximidade: capacidade que um elemento tem para se relacionar com todos ou o maior número possível de elementos da rede.

A metodologia utilizada neste artigo é a análise de citação e/ou cocitação. Segundo Sharplin e Mabry 
(1985), essa análise baseia-se na premissa de que os artigos mais citados, e consequentemente seus autores, exercem maior influência sobre a área ou tema de pesquisa estudado do que os artigos com menor citação. Ademais, White e Griffith (1981) salientam que a análise de cocitação representa a "visão do campo de estudo sobre si mesmo". Conforme exposto por Pilkington e Meredith (2009), a análise de citação possui deficiências mas, com as devidas considerações, fornece informações úteis para avaliar a influência de autores e de publicações. Adicionalmente, os autores também destacam que existe o problema de identificar a pessoa correta (autor) entre o conjunto com o mesmo nome. Parte dessa deficiência é decorrente das diversidades entre as normas que regem os órgãos de publicação, pontuando ou abreviando nomes de formas diferentes.

Assim como no trabalho de Pilkington e Meredith (2009), este artigo trata de um campo específico, relativamente estreito (em consolidação) e, portanto, foi possível minimizar o viés citado acima ao padronizar as referências e redobrar a atenção aos nomes dos autores para identificá-los corretamente, de forma que toda a pontuação fosse padronizada, assim como as abreviaturas e outros detalhes menores.

Para operacionalizar o estudo de citação e cocitação utilizando redes de relacionamento, foram realizadas pesquisas em bases de dados com algumas palavras-chave que objetivaram cobrir a relação entre as áreas de gestão estratégica de operações e sustentabilidade. As palavras-chave foram obtidas a partir da definição do 3BL, envolvendo aspectos ambientais, sociais e econômicos. Já em gestão estratégica de operações utilizaram-se palavras-chave que definem o seu conteúdo e/ou estrutura. 0 Quadro 2 apresenta as palavras-chave utilizadas.

É importante destacar que a pesquisa foi realizada com o cruzamento dessas palavras-chave. Esses cruzamentos geraram nove duplas, que foram utilizadas

Quadro 2. Palavras-chave utilizadas no levantamento dos artigos.

\begin{tabular}{ll}
\hline \multicolumn{1}{c}{ Gestão estratégica de operações } & \multicolumn{1}{c}{ Sustentabilidade } \\
\hline Estratégia de operações & Sustentabilidade econômica \\
Sistema de medição de desempenho & Sustentabilidade ambiental \\
Medida de desempenho & Sustentabilidade social \\
\hline
\end{tabular}

para realizar as pesquisas nas bases de dados. Por exemplo, utilizou-se "estratégia de operações" em conjunto com "sustentabilidade econômica", "sustentabilidade ambiental" e "sustentabilidade social". Esse conjunto de palavras foi utilizado para realizar as pesquisas nas bases de dados, identificando-as nos campos título, resumo e palavras-chave. As bases de dados pesquisadas estão na sua grande maioria disponíveis no portal de periódicos da Capes e representam, dentre outras, a Emerald Library, Science Direct da Elsevier, Springer e Scielo, sendo que 55\% de todos os artigos utilizados no estudo são provenientes da Emerald Library.

Os artigos obtidos nas pesquisas nas bases de dados passaram por uma triagem obedecendo aos seguintes critérios: primeiro foram selecionados os artigos que possuíam uma das palavras-chave no título, resumo ou no campo de palavras-chave propriamente dito; segundo, ao se eleger esses artigos, lia-se o resumo para identificar se estavam dentro do escopo do estudo. Após a triagem final, foram selecionados 105 artigos para a análise de citação e cocitação. As referências desses artigos foram registradas. Para construir o gráfico de redes de relacionamento foram selecionados os 75 principais autores. Essa decisão foi baseada em uma análise de Pareto, visto que a exibição de todos os autores resultaria em um gráfico poluído visualmente. Esses 75 autores representam, dentro do corpus de 105 artigos, aproximadamente $14 \%$ de todas as 6.790 citações obtidas.

Foi construída uma tabela eletrônica em Excel $^{\circledR}$ (Tabela 1) com o objetivo de orientar os pesquisadores a mapear todas as informações sobre os dados das publicações selecionadas, para posteriormente auxiliá-los na construção da matriz de relacionamentos que alimenta possíveis cenários de estudo no software UCINET $6.109^{\circledR}$.

Como o objetivo principal deste trabalho é analisar informações vinculadas a redes de relacionamento de um grupo de autores e de palavras-chave, após o desenvolvimento da planilha eletrônica uma matriz de relacionamentos é construída com base na quantidade de citações que os autores selecionados realizaram em seus artigos. Essas citações são referências a outros autores, identificados na amostra de 105 artigos encontrados nas bases de dados.

Tabela 1. Catálogo de publicações.

\begin{tabular}{|c|c|c|c|c|c|c|c|c|c|c|}
\hline & Área & $\begin{array}{c}\text { Base de } \\
\text { dados }\end{array}$ & Tipo & $\begin{array}{l}\text { Autores } \\
\text { citados }\end{array}$ & Referências & Título & Autor & Ano & $\begin{array}{c}\text { País de } \\
\text { publicação }\end{array}$ & $\begin{array}{c}\text { Local de } \\
\text { publicação/editora }\end{array}$ \\
\hline 1 & $\begin{array}{l}\text { Gestão estratégica } \\
\text { de operações }\end{array}$ & $X X$ & artigo & 66 & 34 & $X X$ & $X X$ & 2004 & EUA & $X X$ \\
\hline 2 & $\begin{array}{l}\text { Operações em } \\
\text { serviços }\end{array}$ & $X X X$ & artigo & 40 & 31 & $X X X$ & $X X X$ & 1994 & Inglaterra & $X X X$ \\
\hline
\end{tabular}


Para o desenvolvimento do gráfico de redes de relacionamento utilizando o software UCINET $6.109^{\circledR}$ como ferramenta de apoio primeiramente é necessário a construção de uma matriz quadrada para alimentar as informações. Tais matrizes devem ser desenvolvidas considerando um sistema de fluxos unidirecionais. As matrizes podem ser desenvolvidas no próprio software UCINET $6.109^{\circledR}$ ou importadas de uma planilha eletrônica (e.g. Excel $^{\circledR}$ ).

Para contabilizar os autores que mais contribuíram para o tema de pesquisa, isto é, os que mais receberam citações, foi desenvolvido um processo de contagem das citações (artigos e autores) que constavam no referencial bibliográfico dos artigos selecionados. A contagem foi realizada manualmente, utilizando-se como ferramentas de apoio planilhas eletrônicas especialmente desenvolvidas para armazenar as informações levantadas junto às bases de dados escolhidas.

Ao definir os principais autores, foi realizada uma segunda contagem. Para tanto, foram separados os artigos publicados pelos 75 principais autores, dentro de um corpus de 105 artigos. A partir disso, foi identificada a relação existente entre os autores. Essa relação permitiu gerar a planilha de citação e cocitação que, por sua vez, foi utilizada para gerar os gráficos de redes de relacionamento no UCINET $6.109^{\circledR}$. Para gerar a planilha, selecionava-se o artigo publicado, por exemplo, por R. D. Klassen e realizava-se a contagem de quantas vezes ele citou M. E. Porter em suas referências, que neste trabalho resultou em uma citação. Após finalizada a contagem de citação e cocitação dos 75 principais autores, foi possível gerar os gráficos de redes de relacionamento.

A pesquisa apresentada neste artigo está subdividida em quatro etapas principais, sendo a primeira um estudo de natureza teórico-conceitual, a segunda, a definição da estratégia de pesquisa, a terceira, a descrição do planejamento de pesquisa, para na etapa final serem desenvolvidas a análise $\mathrm{e}$ a interpretação dos dados levantados. 0 Quadro 2 sintetiza o desenvolvimento da pesquisa.

Os resultados e as interpretações da coleta de dados são apresentados na próxima seção.

\section{Análise e interpretação de resultados}

Para realizar a pesquisa de citação e cocitação, selecionaram-se artigos publicados nos últimos dez anos em temas relacionados a sustentabilidade e gestão estratégica de operações. É importante destacar que os artigos obtidos do ano de 2010 incluem as publicações realizadas até o mês de julho. A partir desses dados foi gerado o gráfico apresentado na
Figura 1, que mostra a distribuição de publicações realizadas por ano. É possível observar que existe um pico de publicações no ano de 2006, com 16 artigos. Além disso, o ano de 2010, apesar de ainda não finalizado, já totaliza 7 artigos publicados, número de artigos maior que nos anos de 2000, 2001 e 2002. Apesar de o corpus de artigos utilizado ser da última década, pôde-se observar ao longo do estudo, nas citações, publicações a partir do ano de 1922, que em questão refere-se ao autor Alfred J. Lotka, que publicou o trabalho Contribution to the energetics of evolution and natural selection as a physical principle, além deste, pode-se citar o trabalho de J. Hicks, de 1946: Value and capital: an inquiry into some fundamental principles of economic theory. Entretanto, o marco histórico desta área está vinculado à publicação, em 1987, do Report of the world commission on environment and development: our common future, mais conhecido como Brundtland report. Ademais, a grande variação apresentada na Figura 1 pode significar que a pesquisa em gestão de operações e sustentabilidade está em fase de crescimento e consolidação e, portanto, ainda não atingiu um estado de maturidade de publicações.

A partir da contagem e registro das referências foi possível identificar uma lista com cerca de 6.790 citações nos 105 artigos pesquisados. A Tabela 2 apresenta os 75 principais autores e sua representatividade dentro da população em porcentagem. 0 critério para essa seleção foi determinado como: os autores que possuiam acima de cinco citações.

Apesar do número significativo de citações, 868 (oitocentas e sessenta e oito), atribuídas aos 75 autores selecionados, a soma delas não chegou a 15\% do total de referências contidas nos 105 artigos estudados, o que demonstra um grande número de autores relacionados ao tema da pesquisa e pouca convergência para alguns dos líderes principais.

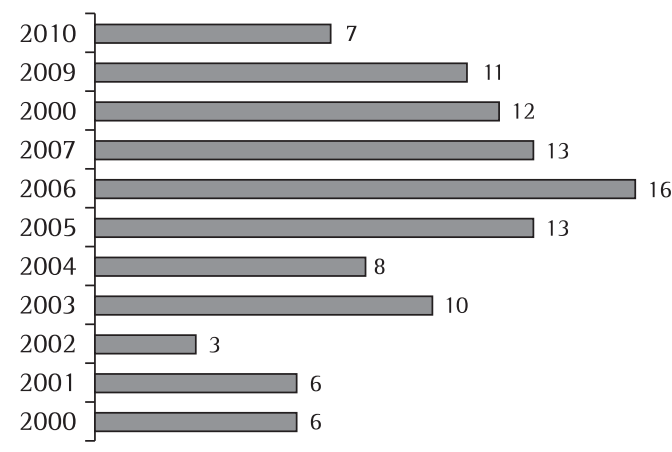

Figura 1. Distribuição de publicações por ano. 
Pôde-se observar também que o índice de artigos nacionais que abordam o tema de sustentabilidade nas bases pesquisadas não foi representativo, de forma que nenhum autor nacional é citado entre os 75 principais.

Entre os autores mais citados estão R. D. Klassen e M. E. Porter. Deve ser considerado que a construção da Tabela 2 não excluiu autocitações, o que poderia introduzir um determinado viés na análise desenvolvida. 0 software de análise de redes de relacionamento desconsidera as autocitações, isto é, a diagonal da matriz não é considerada na formação das redes.

Baseando-se nas informações apresentadas nas Tabelas 1 e 2 foi elaborada a matriz de citação e cocitação que alimentou o software de análise de redes de relacionamento. A rede representada na Figura 2, obtida a partir da pesquisa, demonstra, entre outros aspectos, que existe forte ligação entre alguns autores, como no caso de S. L. Hart e V. Veleva. Visualmente, observa-se a intensidade do relacionamento entre os autores pela espessura da ligação existente entre eles e pela sua proximidade no diagrama. Outra relação que se destaca é entre R. Gray e C. A. Adams. Um outro ponto importante a ser destacado é a formação de clusters em algumas regiões da rede. As concentrações se formam tendo normalmente como ponto focal um autor que é citado significativamente ou que tem grande produção científica e cita consistentemente

Tabela 2. 0s 75 principais autores.

\begin{tabular}{|c|c|c|c|c|c|c|c|c|c|}
\hline & Autor & Qtde. & Acumulado & $\begin{array}{c}\text { Acumulado } \\
(\%)\end{array}$ & & Autor & Qtde. & Acumulado & $\begin{array}{c}\text { Acumulado } \\
(\%)\end{array}$ \\
\hline 1 & KLASSEN, R. D. & 31 & 31 & 0,27 & 39 & HAWKEN, P. & 10 & 573 & 5,22 \\
\hline 2 & PORTER, M. E. & 24 & 55 & 0,55 & 40 & SCHMIDHEINY, S. & 10 & 583 & 5,31 \\
\hline 3 & FREEMAN, R. E. & 20 & 75 & 0,76 & 41 & SHRIVASTAVA, P. & 10 & 593 & 5,40 \\
\hline 4 & KORHONEN, J. & 20 & 95 & 0,93 & 42 & SPENCE, L. J. & 10 & 603 & 5,49 \\
\hline 5 & HART, S. L. & 20 & 115 & 1,11 & 43 & VACHON, S. & 10 & 613 & 5,57 \\
\hline 6 & GRAY, R. & 19 & 134 & 1,28 & 44 & BEBBINGTON, J. & 10 & 623 & 5,66 \\
\hline 7 & EPSTEIN, M. J. & 19 & 153 & 1,45 & 45 & LOVELL, C. A. K. & 9 & 632 & 5,74 \\
\hline 8 & ADAMS, C. A. & 18 & 171 & 1,62 & 46 & JASCH, C. & 9 & 641 & 5,82 \\
\hline 9 & ELKINGTON, J. & 18 & 189 & 1,78 & 47 & ISAKSSON, R. & 9 & 650 & 5,90 \\
\hline 10 & LAVE, L. B. & 18 & 207 & 1,93 & 48 & SHARMA, S. & 9 & 659 & 5,98 \\
\hline 11 & DALY, H. & 18 & 225 & 2,09 & 49 & VANDERLINDE, C. & 9 & 668 & 6,06 \\
\hline 12 & SARKIS, J. & 17 & 242 & 2,25 & 50 & ZADEK, S. & 9 & 677 & 6,14 \\
\hline 13 & WASSENHOVE, V. L. N. & 17 & 259 & 2,40 & 51 & PATTEN, D. M. & 9 & 686 & 6,22 \\
\hline 14 & SCHALTEGGER, S. & 16 & 275 & 2,55 & 52 & WICKS, A. C. & 9 & 695 & 6,30 \\
\hline 15 & HANDFIELD, R. B. & 16 & 291 & 2,69 & 53 & DOVERS, S. & 9 & 704 & 6,37 \\
\hline 16 & VELEVA, V. & 15 & 306 & 2,83 & 54 & FOUTS, P. A. & 9 & 713 & 6,45 \\
\hline 17 & WADDOCK, S. A. & 15 & 321 & 2,96 & 55 & BANSAL, P. & 8 & 721 & 6,52 \\
\hline 18 & WAGNER, M. & 14 & 335 & 3,09 & 56 & ELLENBECKER, M. & 8 & 729 & 6,59 \\
\hline 19 & MELNYK, S. A. & 14 & 349 & 3,22 & 57 & FREEDMAN, M. & 8 & 737 & 6,66 \\
\hline 20 & SIEGEL, D. & 13 & 362 & 3,34 & 58 & RUSSO, M. V. & 8 & 745 & 6,73 \\
\hline 21 & CARROLL, A. B. & 12 & 374 & 3,46 & 59 & WEHRMEYER, W. & 8 & 753 & 6,80 \\
\hline 22 & CARTER, C. R. & 12 & 386 & 3,56 & 60 & $\mathrm{ZHU}, \mathrm{Q}$. & 8 & 761 & 6,88 \\
\hline 23 & COSTANZA, R. & 12 & 398 & 3,67 & 61 & CHRISTMANN, P. & 8 & 769 & 6,95 \\
\hline 24 & MCWILLIAMS, A. & 12 & 410 & 3,77 & 62 & SMITH, A. D. & 8 & 777 & 7,02 \\
\hline 25 & FlGGE, F. & 12 & 422 & 3,88 & 63 & GLADWIN, T. N. & 8 & 785 & 7,09 \\
\hline 26 & AZAPAGIC, A. & 11 & 433 & 3,98 & 64 & AGLE, B. R. & 7 & 792 & 7,15 \\
\hline 27 & BRENT, A. C. & 11 & 444 & 4,08 & 65 & COUSINS, P. D. & 7 & 799 & 7,21 \\
\hline 28 & GROSSKOPF, S. & 11 & 455 & 4,18 & 66 & DAHLSRUD, A. & 7 & 806 & 7,27 \\
\hline 29 & HAHN, T. & 11 & 466 & 4,27 & 67 & GRAEDEL, T. E. & 7 & 813 & 7,33 \\
\hline 30 & JONES, T. M. & 11 & 477 & 4,37 & 68 & JAMES, P. & 7 & 820 & 7,39 \\
\hline 31 & TYTECA, D. & 11 & 488 & 4,47 & 69 & LABUSCHAGNE, C. & 7 & 827 & 7,46 \\
\hline 32 & WHYBARK, D. C. & 11 & 499 & 4,56 & 70 & PEARCE, D. & 7 & 834 & 7,52 \\
\hline 33 & WOOD, D. J. & 11 & 510 & 4,66 & 71 & PERDAN, S. & 7 & 841 & 7,58 \\
\hline 34 & WALTON, S. V. & 11 & 521 & 4,76 & 72 & RENNINGS, K. & 7 & 848 & 7,64 \\
\hline 35 & GRAVES, S. B. & 11 & 532 & 4,85 & 73 & VREDENBURG, H. & 7 & 855 & 7,70 \\
\hline 36 & PRESTON, L. E. & 11 & 543 & 4,95 & 74 & FRIEDMAN, M. & 7 & 862 & 7,76 \\
\hline 37 & FET, A. M. & 10 & 553 & 5,05 & 75 & ALLEN, D. T. & 6 & 868 & 7,82 \\
\hline 38 & FÄRE, R. & 10 & 563 & 5,13 & & Outros & 10.506 & 11.374 & 100,00 \\
\hline
\end{tabular}


um determinado conjunto de autores. R. D. Klassen, considerado o autor mais citado de acordo com a Tabela 2, forma, junto com S. Vachon, um dos clusters mais visíveis da rede. Entretanto, o agrupamento que se forma ao redor de M. Wagner ocupa uma posição mais central e com maior densidade. T. Hahn e F. Figge também centralizam uma rede densa de citações, visto que suas publicações aconteceram em conjunto, em sua grande maioria.

Cada um dos clusters posicionados em pontos diferentes da rede pode representar uma comunidade de pesquisadores com interesses específicos de pesquisa. Os autores que se encontram na periferia são aqueles que, dentre os 75 principais autores, receberam ou citaram um número menor de referências. Esses posicionamentos e conexões podem indicar elos de ligação com outras disciplinas ou áreas do conhecimento. Pode ser visto que os autores do cluster R. D. Klassen e S. Vachon, como S. Melnik e J. Sarkis, entre outros, têm fortes vínculos com estudos em gestão da cadeia de suprimentos.

Pode-se interpretar também o diagrama pelo diâmetro dos nós que identificam o grau de centralidade deles, ou seja, quanto maior o número de interações entre um elemento e os demais, maior será o diâmetro do nó.

Muitas outras análises podem ser realizadas via rede de relacionamento de autores, como as que envolvem estudos de intermediação e de nível de centralização da rede formada. 0 Apêndice 1 apresenta indicadores quantitativos na forma de medidas de centralidade, centralização, intermediação e proximidade para a rede de autores.
Também é possível realizar a análise de palavras-chave por meio das redes de relacionamento, que nesse caso contém 98 nós. A Figura 3 permite identificar os grandes temas de pesquisa em gestão estratégica de operações sustentáveis, via agrupamento de palavras-chave. É possível observar seis principais clusters, sendo eles denominados C.1, C.2, C.3, C.4, C.5 e C.6, que representam estudos da seguinte maneira:

- C.1: Posicionado na periferia da rede, o cluster C.1 relaciona estudos de sistemas de propulsão e combustíveis alternativos;

- C.2: Esse cluster engloba sistemas integrados de gestão, modelos de governança e análise de stakeholders e normas, padrões e guias de referência;

- C.3: Nesse agrupamento é evidente o tema ambiental, particularmente relacionado ao desempenho ambiental das organizações e gestão de recursos naturais, que constituem os maiores nós. Saúde e segurança são temas também trabalhados nesse grupo. Vários estudos relacionados à indústria química estão presentes;

- C.4: É o agrupamento mais denso da rede e associa dois nós principais: desenvolvimento sustentável e responsabilidade social. Um setor que é evidenciado no cluster C.4 é a indústria de transportes, que se associa à emissão de gases e efeito estufa. Estudos desenvolvidos no Japão e Estados Unidos da América do Norte também se destacam no grupo;

- C.5: Estudos referentes ao setor de energia e subprodutos e seus efeitos na cadeia de valor são os destaques desse agrupamento; e

- C.6: 0 sexto grupo caracteriza-se por estudos de natureza quantitativa. Aspectos econômicos, sistemas de informação e a gestão de riscos definem

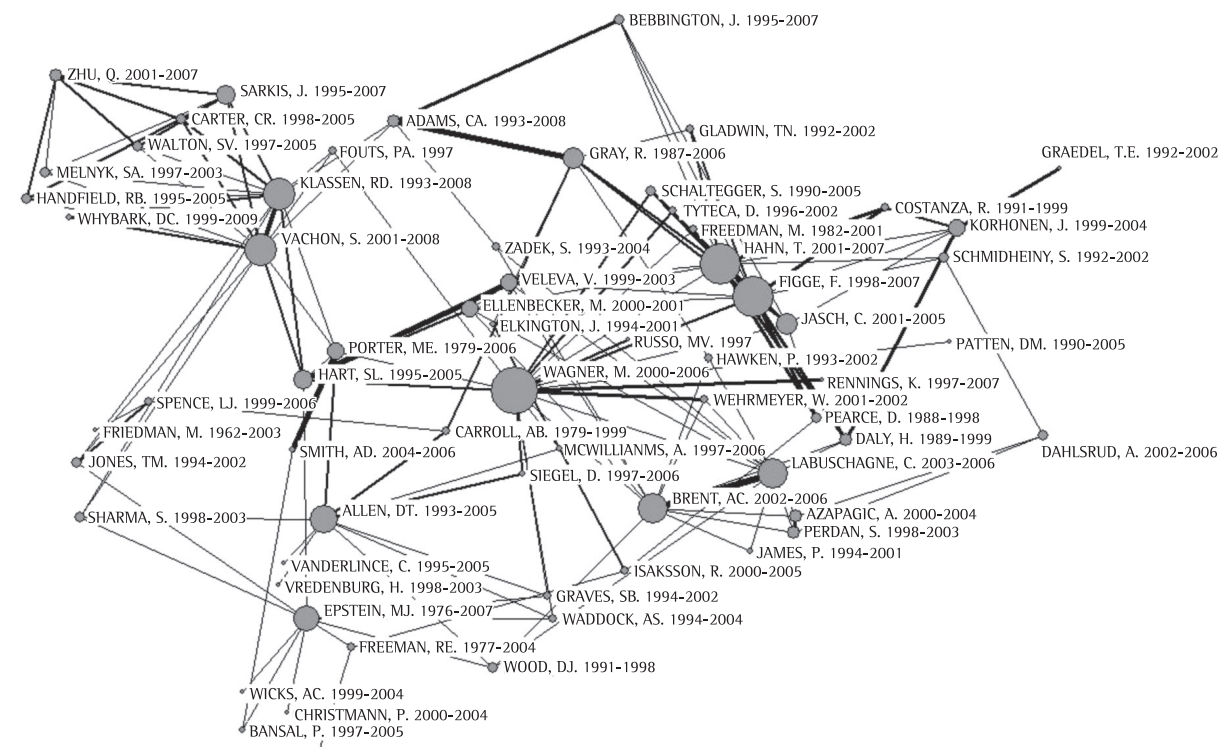

Figura 2. Gráfico de redes de relacionamento para os autores. 
os temas estudados nesse agrupamento. Modelos que favorecem o desenvolvimento de capacitações baseadas na melhoria da eficiência operacional, como a produção enxuta, completam os assuntos estudados nesse grupo.

Os principais periódicos que tratam do tema sustentabilidade na gestão estratégica de operações somam sete títulos, ou seja, 35\% dos artigos do corpus de 105 artigos utilizados nesta pesquisa, conforme ilustrado na Figura 4.

0 periódico de maior destaque é o Journal of Cleaner Production, com 9\% das publicações analisadas. Esse resultado revela-se totalmente coerente ao se analisar a descrição do periódico no sítio eletrônico da base de dados Elsevier:

0 Journal of Cleaner Production serve como um fórum internacional interdisciplinar para a troca de informações e resultados de pesquisa sobre tecnologias, conceitos e políticas destinadas a ajudar a garantir o progresso em direção às sociedades sustentáveis. 0 objetivo é estimular inovação industrial, melhoria e lançamento de novos produtos e implementação de novos processos limpos, produtos e serviços. Também é projetado para estimular o desenvolvimento e implementação de prevenções orientadas por políticas governamentais e programas educativos. Cleaner Production é um conceito que vai além do simples controle da poluição. Trata-se de pesquisa ativa e desenvolvimento de novos processos voltados para a prevenção, materiais e produtos que são menos tóxicos e apresentam mais recursos e eficiência energética. Tais abordagens proativas estão se tornando cada vez mais as principais vias de empresas e governos para garantir produção e serviços ecológica e economicamente viáveis.
Assistência técnica e programas de educação e formação aprofundados estão cada vez mais sendo usados para acelerar a adoção de Cleaner Production e de Cleaner Products and Services por indústrias, organizações de serviços, governos, universidades e cidadãos particulares [...] (ELSEVIER, 2010).

Os sete periódicos selecionados estão inseridos no contexto de sustentabilidade e gestão de operações e estão contidos nas mais diversas áreas do conhecimento. 0 Quadro 3 aponta os principais temas discutidos pelos periódicos distribuídos entre as três perspectivas do Triple Bottom line.

0 presente trabalho caracteriza a pesquisa de temas relacionados à sustentabilidade no escopo delimitado pela gestão estratégica de operações.

A partir das informações geradas pela análise de redes e indicadores foi possível construir o Quadro 4, que estabelece relações entre os principais temas de pesquisa estudados, os agrupamentos de palavraschave C.1, C.2, C.3, C.4, C.5 e C.6 e os principais autores identificados na pesquisa. Além disso, são sugeridos desdobramentos na forma de questões de pesquisa, conforme apresentado no Quadro 5.

De forma a complementar as informações presentes no Quadro 4, relatórios e documentos de referência publicados pelas seguintes instituições devem ser considerados em qualquer estudo que se faça no tema sustentabilidade: GRI - Global Reporting Initiative, WCED - World Commission on Environment and Development, WBCSD - World Business Council for Sustainable Development, ISO - International Organization for Standardization, OECD - Organization

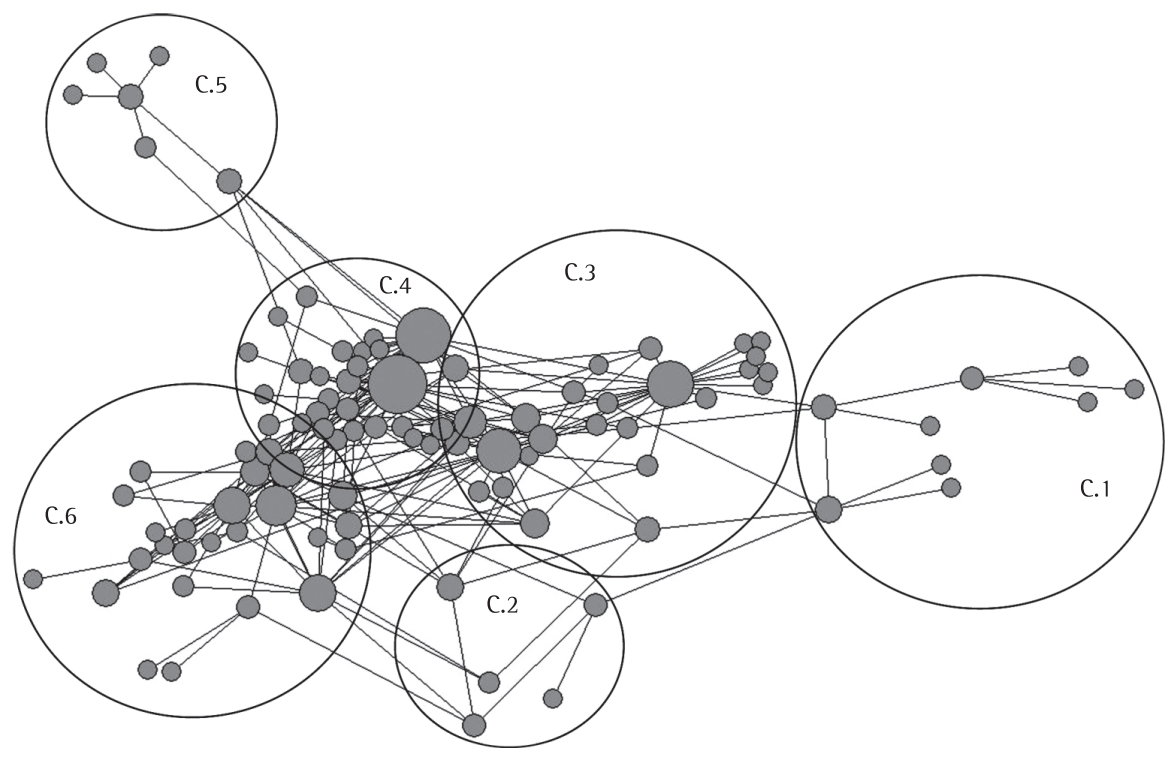

Figura 3. Gráfico de redes de relacionamento para as palavras-chave. 
for Economic Co-operation and Development, EPA - Environmental Protection Agency.

A partir das análises realizadas pôde-se observar um crescente interesse pelos estudos relacionados à sustentabilidade na área de gestão de operações. Há número significativo de publicações no tema. A distribuição de trabalhos apresentada é contexto dependente, ou seja, é fruto da amostra selecionada de artigos.
No que se refere às palavras-chave, diversos são os temas associados à sustentabilidade, comprovando a amplitude de seu escopo e empregabilidade no contexto da gestão de operações. Nota-se grande representatividade de estudos acerca de gestão da cadeia de suprimentos, bem como estudos ambientais e sociais que firmam e consolidam os três aspectos propostos no modelo 3BL. Destaca-se também a difusão do conceito sustentabilidade tanto na síntese

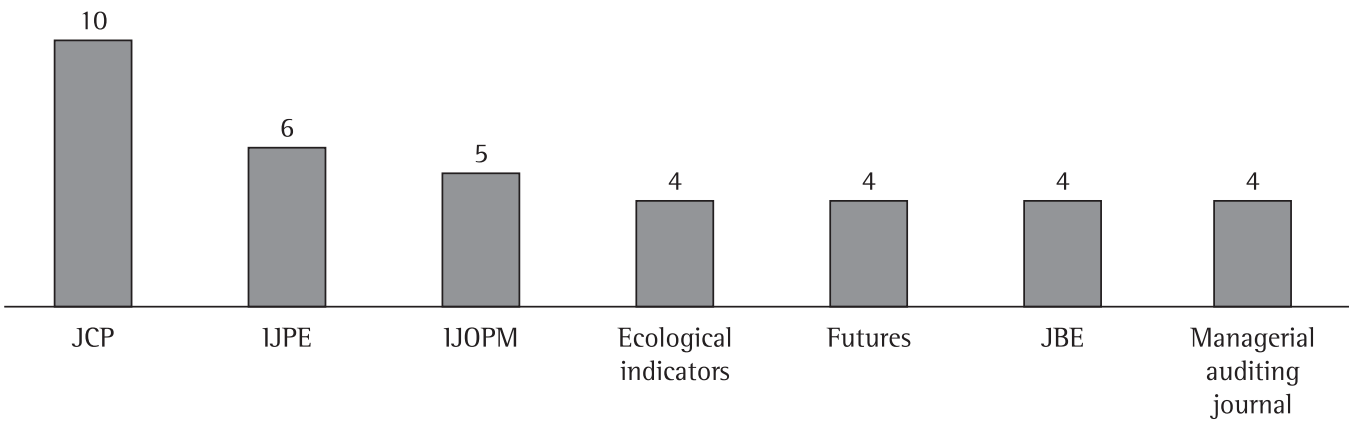

Figura 4. Principais periódicos de gestão de operações e sustentabilidade.

Quadro 3. Etapas da pesquisa.

\begin{tabular}{|c|c|}
\hline Etapas da pesquisa & Descrição \\
\hline $\begin{array}{l}\text { Etapa } 1 \text { - Estudo } \\
\text { teórico-conceitual }\end{array}$ & $\begin{array}{l}\text { No estudo de natureza teórico-conceitual é realizada uma descrição completa do tema central da pesquisa com o } \\
\text { objetivo principal de apresentar os seus conceitos fundamentais. Para desenvolvimento desse trabalho, assuntos } \\
\text { relacionados à Gestão estratégica de operações, Estratégia de operações, Sistemas de medição de desempenho e } \\
\text { sustentabilidade delimitam o conjunto de conceitos fundamentais para a pesquisa. }\end{array}$ \\
\hline $\begin{array}{c}\text { Etapa } 2 \text { - Estratégia de } \\
\text { pesquisa }\end{array}$ & $\begin{array}{l}\text { A estratégia de pesquisa é definida no escopo da pesquisa bibliométrica, particularmente as relacionadas a estudos } \\
\text { de citação e/ou cocitação. } 0 \text { estudo busca realizar uma descrição das características e relações das variáveis sobre } \\
\text { o assunto estudado com o objetivo de estudar as características de um grupo ou de uma comunidade que estuda } \\
\text { sustentabilidade no contexto da gestão estratégica de operações. Redes de relacionamento são utilizadas para } \\
\text { analisar autores e palavras-chave, identificando suas relações e interações. }\end{array}$ \\
\hline $\begin{array}{c}\text { Etapa } 3 \text { - Planejamento da } \\
\text { pesquisa }\end{array}$ & $\begin{array}{l}0 \text { planejamento de pesquisa apresenta informações operacionais e instrumentais sobre a estrutura de } \\
\text { investigação, orientando o pesquisador no desenvolvimento do processo de amostragem, técnicas de coletas } \\
\text { de dados, organização dos dados e construção de planilhas eletrônicas e quadros descritivos com o intuito de } \\
\text { alimentar o software UCINET } 6.109^{\oplus} \text {. }\end{array}$ \\
\hline $\begin{array}{c}\text { Etapa } 4 \text { - Análise e } \\
\text { interpretação de resultados }\end{array}$ & $\begin{array}{l}\text { Nesta etapa são discutidos os resultados gerados pelos indicadores e estatísticas do software UCINET } 6.109^{\circ} \\
\text { em diferentes cenários de análise. Os gráficos, indicadores e estatísticas permitem desenvolver uma análise } \\
\text { fundamentada nas redes de relacionamento, permitindo uma completa caracterização dos temas de estudo } \\
\text { escolhidos e da produção científica na área. }\end{array}$ \\
\hline
\end{tabular}

Quadro 4. Abordagem dos periódicos classificados nas três perspectivas do Triple Bottom line.

\begin{tabular}{|c|c|c|}
\hline Perspectiva econômica & Perspectiva social & Perspectiva ambiental \\
\hline $\begin{array}{c}\text { Melhoria de processos } \\
\text { operacionais }\end{array}$ & Responsabilidade social corporativa & $\begin{array}{l}\text { Indicadores ecológicos e do meio } \\
\text { ambiente }\end{array}$ \\
\hline Energia renovável & $\begin{array}{c}\text { Implementação de práticas sustentáveis por meio da } \\
\text { sociedade }\end{array}$ & Sistemas de gestão ambiental \\
\hline Gestão da cadeia de suprimentos & Politicas governamentais sustentáveis & Tecnologias "amigas do meio ambiente" \\
\hline Planejamento e controle & Iniciativas educacionais & Ciclo de vida de produtos e serviços \\
\hline Gestão de pessoas nas operações & Indicadores sociais e produtividade & Avaliação da performance ambiental \\
\hline Logística & Ética no negócio & Redução de riscos ambientais \\
\hline \multicolumn{3}{|l|}{ Customização em massa } \\
\hline \multicolumn{3}{|l|}{ Design do produto } \\
\hline \multicolumn{3}{|l|}{ Estratégia operacional } \\
\hline \multicolumn{3}{|l|}{ Gestão de desempenho } \\
\hline \multicolumn{3}{|l|}{ Gestão da qualidade } \\
\hline Auditorias & & \\
\hline
\end{tabular}


e evolução de modelos teóricos como nas práticas organizacionais. Essa segunda observação é feita a partir do uso da informação contida em diversos relatórios de sustentabilidade baseados no GRI, um dos principais documentos citados nas pesquisam que avaliam as práticas organizacionais em operações sustentáveis.

As redes formadas por palavras-chave demonstram falta de conexão entre os principais nós, o que evidencia possíveis gaps de estudos. A fim de preencher essas lacunas, são propostos, pelos autores, alguns temas formados pelo cruzamento entre as palavras, além de questões de pesquisas a serem respondidas sobre esses temas.

Por meio dos resultados obtidos e das inferências cabiveis, entende-se a grande importância de práticas ambientais e sociais que garantam equilíbrio no atendimento das necessidades econômicas e de desenvolvimento do cenário global.

\section{Conclusão}

0 estudo apresenta uma investigação de natureza bibliográfica que utiliza medidas quantitativas e representações gráficas para descrever a pesquisa no tema sustentabilidade delimitada pela gestão estratégica de operações. A análise se restringiu a publicações nos últimos dez anos e trabalhou um corpus de 105 artigos com um total de 6.790 referências. Os 75 principais autores, que representam 14\% do total de citações, foram utilizados para a construção das redes de relacionamento. Das palavras-chave,

Quadro 5. Proposição de temas e questões de pesquisa para futuros estudos.

\begin{tabular}{|c|c|c|c|c|}
\hline Cluster & Autores & Principais palavras-chave & Temas propostos & Questões de pesquisa \\
\hline C. 1 & $\begin{array}{l}\text { L. Lave, } \\
\text { S. Vachon, } \\
\text { R. Klassen }\end{array}$ & $\begin{array}{c}\text { Propulsion system, } \\
\text { Alternative fuels, Construct, } \\
\text { Global economy, Validation, } \\
\text { German companies }\end{array}$ & $\begin{array}{l}\text { Combustíveis alternativos } \\
\text { como fomentadores de uma } \\
\text { economia e desenvolvimento } \\
\text { sustentáveis }\end{array}$ & $\begin{array}{l}\text { De que maneira as novas tecnologias em sistemas } \\
\text { de propulsão, desenvolvendo uma nova matriz } \\
\text { energética, podem influenciar os modelos de redes } \\
\text { de produção? } \\
\text { Em que medida as fontes alternativas de energia } \\
\text { podem contribuir para o desenvolvimento } \\
\text { sustentável das operações? }\end{array}$ \\
\hline C. 2 & $\begin{array}{l}\text { C. Brent, C. } \\
\text { Labuschagne, } \\
\text { R. lsaksson, } \\
\text { M. Porter, }\end{array}$ & $\begin{array}{l}\text { Management information } \\
\text { system, Stakeholder } \\
\text { analysis, Control systems, } \\
\text { 1SO 9001, Standardization }\end{array}$ & $\begin{array}{l}\text { Desenvolvimento de modelos } \\
\text { de referência para a gestão de } \\
\text { operações sustentáveis e o seu } \\
\text { marco normativo e regulatório }\end{array}$ & $\begin{array}{l}\text { Como os modelos de referência, contidos em } \\
\text { diferentes normas e padrões influenciam as práticas } \\
\text { de operações sustentáveis? } \\
\text { Como os padrões 1SO constroem referências para o } \\
\text { projeto de sistemas de gestão sustentáveis? }\end{array}$ \\
\hline C. 3 & $\begin{array}{l}\text { S. Vachon, } \\
\text { R. Klassen, } \\
\text { V. Veleva, } \\
\text { M. Hart, } \\
\text { J. Sarkis, } \\
\text { Q. Zhu, } \\
\text { M. Epstein, } \\
\text { M. Wagner, } \\
\text { H. Daly }\end{array}$ & $\begin{array}{l}\text { Environmental } \\
\text { performance, Natural } \\
\text { resources, Chemical } \\
\text { industries, Health and } \\
\text { safety, Green supply chain } \\
\text { management }\end{array}$ & $\begin{array}{l}\text { As práticas adotadas na } \\
\text { indústria de processos e na } \\
\text { sua cadeia de suprimentos e o } \\
\text { desenvolvimento de redes de } \\
\text { operações sustentáveis }\end{array}$ & $\begin{array}{l}\text { Quais práticas ambientais são adotadas pelas } \\
\text { indústrias de processos na busca do desenvolvimento } \\
\text { sustentável de suas operações? } \\
\text { Como as práticas contidas nos sistemas SMS } \\
\text { (segurança, meio ambiente e saúde) se relacionam } \\
\text { com um modelo fundamentado em operações } \\
\text { sustentáveis? }\end{array}$ \\
\hline C. 4 & $\begin{array}{l}\text { M. Wagner, } \\
\text { A. Fet, } \\
\text { R. Isaksson, } \\
\text { M. Melnyk, } \\
\text { R. Handfield, } \\
\text { S. Walton, } \\
\text { A. Smith }\end{array}$ & $\begin{array}{l}\text { Sustainable development, } \\
\text { Social corporate } \\
\text { responsibility, Transports, } \\
\text { Automotive industry, } \\
\mathrm{CO}_{2} \text { abatement, Agile } \\
\text { manufacturing, Supply } \\
\text { chain management, } \\
\text { Greenhouse gas emission, } \\
\text { Japan, United States of } \\
\text { America }\end{array}$ & $\begin{array}{l}\text { A responsabilidade } \\
\text { social corporativa como } \\
\text { fator determinante no } \\
\text { equilíbrio das operações } \\
\text { e na fundamentação do } \\
\text { desenvolvimento de modelos } \\
\text { de gestão de operações } \\
\text { sustentáveis }\end{array}$ & $\begin{array}{l}\text { Como as estratégias de responsabilidade social se } \\
\text { relacionam com o desenvolvimento sustentável das } \\
\text { redes de operações? } \\
\text { Quais os benefícios decorrentes das práticas } \\
\text { de responsabilidade social corporativa para } \\
\text { a sustentabilidade das operações? Quais são } \\
\text { as melhores práticas adotadas pela indústria } \\
\text { automobilística no que se refere ao desenvolvimento } \\
\text { sustentável das suas operações? }\end{array}$ \\
\hline C. 5 & $\begin{array}{l}\text { J. Korhonen, } \\
\text { F. Figge, } \\
\text { T. Hahn, } \\
\text { D. Allen }\end{array}$ & $\begin{array}{c}\text { Energy, small and } \\
\text { medium enterprises, Value } \\
\text { management, Industry, } \\
\text { By-product, Value added }\end{array}$ & $\begin{array}{l}\text { A gestão estratégica de } \\
\text { recursos energéticos e a } \\
\text { agregação de valor na cadeia } \\
\text { de suprimentos }\end{array}$ & $\begin{array}{l}\text { Quais são as oportunidades de melhoria do consumo } \\
\text { de energia nas redes produtivas? } \\
\text { De que maneira as redes de operações podem } \\
\text { se beneficiar dos subprodutos gerados em seus } \\
\text { processos produtivos pela gestão estratégica do } \\
\text { insumo energia? } \\
\text { Como a gestão estratégica do insumo energia pode } \\
\text { contribuir para o desenvolvimento de operações } \\
\text { sustentáveis? }\end{array}$ \\
\hline C. 6 & $\begin{array}{l}\text { M. Wagner, } \\
\text { R. Klassen, } \\
\text { J. Sarkis }\end{array}$ & $\begin{array}{l}\text { Economic sustainability, } \\
\text { Accountability, Assessment, } \\
\text { Operations management, } \\
\text { Cleaner production, } \\
\text { Opportunity cost }\end{array}$ & $\begin{array}{l}\text { Sustentabilidade dos } \\
\text { modelos de produção: o } \\
\text { desafio da adequação dos } \\
\text { sistemas de produção para o } \\
\text { desenvolvimento sustentável }\end{array}$ & $\begin{array}{l}\text { Quais são as métricas que definem a dimensão } \\
\text { econômica do modelo 3BL? Quais são as dimensões } \\
\text { de desempenho associadas ao valor agregado na } \\
\text { produção de bens e serviços? } \\
\text { A filosofia Lean constitui um elemento de definição } \\
\text { de valor em operações sustentáveis? }\end{array}$ \\
\hline
\end{tabular}


98 definiram o conjunto analisado nas redes de relacionamento, resultando em seis agrupamentos temáticos. Verificou-se, a partir dos resultados encontrados, que o tema não está consolidado e tende a apresentar números ainda mais significativos de publicações nos próximos anos.

Um fato importante a ser destacado neste trabalho é que no desenvolvimento da pesquisa foram identificadas muitas citações de documentos publicados por instituições. Apesar disso, esses documentos não foram formalmente considerados nas pesquisas em termos de autoria, embora constituam um importante referencial para o desenvolvimento da área.

A consolidação do tema ainda está longe de ser atingida, o que ocasiona interpretações diversas sobre os resultados encontrados. Da mesma forma, a não consolidação do tema limitou o estudo por nas informações encontradas não apresentar convergência. lsso pode ser observado pela porcentagem de autores significativos somando apenas 14\% do total encontrado. Por outro lado, percebe-se um grande interesse pelo tema em diversos grupos de pesquisa e comunidades, condição observada nos periódicos de diferentes disciplinas nos quais são publicados os estudos e nas análises dos clusters da rede de palavras-chave.

Por fim, os autores sugerem uma relação de temas que necessitam ser discutidos na literatura a fim de contribuir para a consolidação do tema sustentabilidade e gestão de operações, bem como questões de pesquisa, autores-chave e leituras relevantes.

Devido ao grande número de publicações recentes relacionadas ao tema em questão, entende-se que os resultados encontrados são pontuais e tendem a variar levando-se em consideração o intervalo de tempo definido e corpus de artigos estudados.

\section{Referências}

ALEJANDRO, V. A. O.; NORMAN, A. G. Manual introductorio al análisis de redes de relacionamento. Centro de Capacitación y Evaluación para el Desarrollo Rural S.C., 2006. Disponível em: <http://revista-redes.rediris. es/webredes/talleres/Manual_ARS.pdf>. Acesso em: 28 jun. 2010.

ANDRADE, M. A. M.; GOSLING, M.; XAVIER, W. S. Por trás do discurso socialmente responsável da siderurgia mineira. Produção, v. 20, n. 3, p. 418-428, 2010. http://dx.doi. org/10.1590/S0103-65132010005000014

ARAS, G.; AYBARS, A.; KUTLU, O. Managing corporate performance: investigating the relationship between corporate social responsibility and financial performance in emerging markets. International Journal of Productivity and Performance Management, v. 59, n. 3, p. 229-254, 2010. http://dx.doi. org/10.1108/17410401011023573
ARAS, G.; CROWTHER, D. Governance and sustainability: an investigation into the relationship between corporate governance and corporate sustainability. Management Decision, v. 46, n. 3, p. 433-448, 2008. http://dx.doi. org/10.1108/00251740810863870

BREIGER, R. L. The Analysis of Social Networks. In: Handbook of Data Analysis. London: SAGE Publications, 2004. p. 505-526. Disponível em: <http://www.u.arizona. edu/ breiger/NetworkAnalysis.pdf>. Acesso em: 23 jun. 2010.

CABEZAS, H. et al. Sustainability: ecological, social, economic, technological and systems perspectives. Environmental Protection, v. 5, p. 167-180, 2003.

CAPRA, F. As conexões ocultas: ciência para uma vida sustentável. 3. ed. São Paulo: Cultrix, 2003.

COORDENAÇÃO DE APERFEIÇOAMENTO DE PESSOAL DE NÍVEL SUPERIOR - CAPES. Portal de periódicos da CAPES. 2010. Disponível em: <http://novo.periodicos. capes.gov.br/>. Acesso em: 10 ago. 2010.

COSTANZA, R.; DALY, H. Natural capital and sustainable development. Conservation Biology, v. 6, n. 37 p. 37-46, 1992. http://dx.doi.org/10.1046/ j.1523-1739.1992.610037.x

ELKINGTON, J. Cannibals with forks: the triple bottom line of 21st century business. Capstone: Oxford, 1999.

ELSEVIER. Journal of Cleaner Production Aims \& Scope. Disponivel em: <http://www.elsevier.com/ wps/find/journaldescription.cws_home/30440/ description\#description>. Acesso em: 19 ago. 2010.

FIGGE, F.; HAHN, T. Sustainable value added - measuring corporate contributions to sustainability beyond eco-efficiency. Ecological Economics, v. 48, n. 2, p. 173-187, 2004. http://dx.doi.org/10.1016/j. ecolecon.2003.08.005

GLASER, J. A. Corporate responsibility and the triple bottom line. Clean Technologies and Environmental Policy, v. 8 , n. 4 , p. $225-228,2006$. http://dx.doi.org/10.1007/ s10098-006-0067-2

GLOBAL REPORTING INITIATIVE - GRI. Sustainability Reporting Guidelines 2002 on Economic, Environmental and Social Performance. Boston: Global Reporting Initiative, 2002. Disponivel em: <http://www.epeat.net/ Docs/GRl_guidelines.pdf>. Acesso em: 01 ago. 2010.

HARTE, M.J.Ecology, sustainability, and environmentas capital. Ecological Economics, v. 15, n. 2, p. 157-164, 1995. http://dx.doi.org/10.1016/0921-8009(95)00043-7

HICKS, J. Value and capital: an inquiry into some fundamental principles of economic theory. 2nd ed. Oxford: Clarendon Press, 1946.

ISAKSSON, R.; STEIMLE, U. What does GRI-reporting tell us about corporate sustainability? The TQM Journal, v. 21, n. 2, p. 168-181, 2009. http://dx.doi. org/10.1108/17542730910938155

ISAKSSON, R.; GARGAVE, R. Measuring sustainable development using process models. Managerial Auditing Journal, v. 18, n. 8, p. 649-656, 2003. http://dx.doi. org/10.1108/02686900310495142

KRAJNC, D.; GLAVIČ, P. A model for integrated assessment of sustainable development. Resources, Conservation and Recycling, v. 43, n. 2, p. 189-208, 2005.

KEINERT, T. M. M. Sustentabilidade: caminho ou utopia? Revista de Administração Contemporânea, v. 12, n. 2, p. 575-577, 2008. 
LOWELL CENTER. Lowell Center for Sustainable Production. University of Massachusetts Lowell. Disponivel em: $<$ http://www.sustainableproduction.org/>. Acesso em: 5 ago. 2010.

NEUMAYER, E. Weak versus strong sustainability: exploring the limits of two opposing paradigms. Cheltenham: Edward Elgar, 1999.

ORGANIZATION FOR ECONOMIC CO-OPERATION AND DEVELOPMENT - OECD. Corporate Responsibility, Private Initiatives and Public Goals. Paris: OECD Publications, 2001. Disponível em: <http://www.oecd. org/dataoecd/58/54/35315900.pdf>. Acesso em: 1 ago. 2010.

PEARCE, D. Economics, equity and sustainable development. Futures, v. 20, n. 6, p. 598-605, 1988. http://dx.doi. org/10.1016/0016-3287(88)90002-X

PILKINGTON, A.;MEREDITH, J. The evolution of the intellectual structure of operations management - 1980-2006: A citation/co-citation analysis. Journal of Operations Management, v. 27, n. 3, p. 185-202, 2009. http:// dx.doi.org/10.1016/j.jom.2008.08.001

SACHS, 1. Desenvolvimento sustentável: desafio do século XXI. Ambiente \& Sociedade, v. 7, n. 2, p. 214216, 2004. PMid:18449218. http://dx.doi.org/10.1590/ S1414-753X2004000200016

SARKIS, J.; HELMS, M. M.; HERVANI, A. A. Reverse logistics and social sustainability. Corporate Social Responsibility and Environmental Management, v. 17, n. 6, p. 337354, 2010. http://dx.doi.org/10.1002/csr.220

SENGE, P. M. A quinta disciplina: a arte e pratica da organização de aprendizagem. 19. ed. São Paulo: Best Seler, 2005.

SHARPLIN, A.; MARBRY, R. The relative importance of journals used in management research: an alternative ranking. Human Relations, v. 38, n. 1, p. 139-149, 1985. http://dx.doi.org/10.1177/001872678503800204

SIENA, O. Método para avaliar desenvolvimento sustentável: técnicas para escolha e ponderação de aspectos e dimensões. Produção, v. 18, n. 2, p. 359-374, 2008. http://dx.doi.org/10.1590/S0103-65132008000200012
TATE, W. L.; ELLRAM, L. M.; KIRCHOFF, J. O. N. F. Corporate social responsibility reports: a thematic analysis related to supply chain management. Journal of Supply Chain Management, v. 46, n. 1, p. 19-44, 2010. http://dx.doi. org/10.1111/j.1745-493X.2009.03184.x

TÖPFER, K. The triple bottom line economic, social and natural capital. UN Chronicle, v. 36, n. 2, p. 39-41, 2000.

UEDA, $K$. et al. Value creation and decision-making in sustainable society. CIRP Annals - Manufacturing Technology, v. 58, n. 2, p. 681-700, 2009.

VELEVA, V.; ELLENBECKER, M. Indicators of sustainable production: framework and methodology. Journal of Cleaner Production, v. 9, n. 6, p. 519-549, 2001. http:// dx.doi.org/10.1016/S0959-6526(01)00010-5

VELEVA, V. et al. Indicators of sustainable production. Journal of Cleaner Production, v. 9, n. 5, p. 447-452, 2001. http://dx.doi.org/10.1016/S0959-6526(01)00004-X

VEIGA, J. E. Desenvolvimento sustentável: desafio do século XXI. Rio de Janeiro: Garamond Universitária, 2006.

WASSERMAN, S.; FAUST, K. Social network analysis: methods and applications. Cambridge; New York: Cambridge University Press, 1994. http://dx.doi.org/10.1017/ CB09780511815478

WORLD BUSINESS COUNCIL FOR SUSTAINABLE DEVELOPMENT - WBCSD. Signals of Change: Business Progress Toward Sustainable Development. Geneva, 1997. Disponível em: <http://www.wbcsd.org/ includes/getTarget.asp?type $=\mathrm{d} \& \mathrm{id}=0 \mathrm{Tc} 20 \mathrm{~A}>$. Acesso em: 02 ago. 2010.

WORLD COMMISSION ON ENVIRONMENT AND DEVELOPMENT - WCED. Report of the World Commission on Environment and Development: Our Common Future. Genebra, 1987. Disponível em: <http:// www.un-documents.net/wced-ocf.htm>. Acesso em 02 ago. 2010.

WHITE, H.; GRIFFITH, B. C. Author co-citation: a literature measure of intellectual structure. Journal of the American Society for Information Science, v. 32, n. 3, p. 163-171, 1981. http://dx.doi.org/10.1002/ asi.4630320302

\footnotetext{
Abstract

The progress of humankind was remarkable in the last century. Nowadays, an important question is being presented: How long will natural resources be sufficient for attending the increasing demand imposed by the present production models? This paper intends to recover information that founds a new production model genesis, conceived through a new global agenda in which sustainability is placed in a central position. The study is delimited by economics, environmental and social visions, besides its connection with operations management and sustainability. The research is classified as a literature review study, based on CAPES research website database and social network analysis techniques. Social networks were used for identifying keywords and authors' relationships, while descriptive analysis of recovered papers complemented the study of sustainability themes related to present researches on operations management.
}

\section{Researching in sustainable operations: an overview}

\section{Keywords}

Operations management. Strategic management of operations. Sustainable operations. Sustainability. 
Apêndice 1. Quadro de indicadores da rede de autores.

\begin{tabular}{|c|c|c|c|c|c|}
\hline ID/Autores & $\begin{array}{c}\text { Grau de } \\
\text { centralidade }\end{array}$ & Grau de saída & $\begin{array}{l}\text { Grau de } \\
\text { entrada }\end{array}$ & Intermediação & Proximidade \\
\hline ADAMS,CA.1993-2008 & 5 & 15.000 & 2.000 & 126.230 & 863.000 \\
\hline AGLE,BR.1997-1999 & 1 & 0.000 & 1.000 & 0.000 & 918.000 \\
\hline ALLEN,DT.1993-2005 & 11 & 14.000 & 0.000 & 284.142 & 853.000 \\
\hline AZAPAGIC,A.2000-2004 & 5 & 4.000 & 4.000 & 35.327 & 896.000 \\
\hline BANSAL,P.1997-2005 & 2 & 0.000 & 2.000 & 8.393 & 913.000 \\
\hline BEBBINGTON,J.1995-2007 & 4 & 0.000 & 8.000 & 23.176 & 875.000 \\
\hline BRENT,AC.2002-2006 & 12 & 17.000 & 10.000 & 189.550 & 839.000 \\
\hline CARROLL,AB.1979-1999 & 3 & 0.000 & 6.000 & 97.744 & 873.000 \\
\hline CARTER,CR.1998-2005 & 4 & 0.000 & 8.000 & 12.200 & 913.000 \\
\hline CHRISTMANN,P.2000-2004 & 1 & 0.000 & 1.000 & 0.000 & 916.000 \\
\hline COSTANZA,R.1991-1999 & 3 & 0.000 & 10.000 & 0.000 & 900.000 \\
\hline COUSINS,PD.1999-2002 & 0 & 0.000 & 0.000 & 0.000 & 5.625 .000 \\
\hline DAHLSRUD,A.2002-2006 & 4 & 6.000 & 2.000 & 3.075 & 932.000 \\
\hline DALY,H.1989-1999 & 5 & 0.000 & 16.000 & 28.399 & 874.000 \\
\hline DOVERS,S.1996-2006 & 0 & 0.000 & 0.000 & 0.000 & 5.625 .000 \\
\hline ELKINGTON,J.1994-2001 & 2 & 0.000 & 3.000 & 13.904 & 897.000 \\
\hline ELLENBECKER,M.2000-2001 & 6 & 0.000 & 7.000 & 43.205 & 845.000 \\
\hline EPSTEIN,MJ.1976-2007 & 10 & 10.000 & 0.000 & 352.754 & 851.000 \\
\hline FÄRE,R.1985-2007 & 0 & 0.000 & 0.000 & 0.000 & 5.625 .000 \\
\hline FET,AM.2000-2006 & 4 & 5.000 & 3.000 & 3.075 & 932.000 \\
\hline FlGGE,F.1998-2007 & 16 & 28.000 & 5.000 & 217.384 & 838.000 \\
\hline FOUTS,PA.1997 & 3 & 0.000 & 3.000 & 59.257 & 856.000 \\
\hline FREEDMAN,M.1982-2001 & 3 & 0.000 & 3.000 & 0.000 & 863.000 \\
\hline FREEMAN,RE.1977-2004 & 3 & 0.000 & 3.000 & 99.213 & 897.000 \\
\hline FRIEDMAN,M.1962-2003 & 1 & 0.000 & 1.000 & 0.000 & 966.000 \\
\hline GLADWIN,TN.1992-2002 & 3 & 0.000 & 5.000 & 0.000 & 879.000 \\
\hline GRAEDEL,TE.1992-2002 & 1 & 0.000 & 4.000 & 0.000 & 955.000 \\
\hline GRAVES,SB. 1994-2002 & 3 & 0.000 & 3.000 & 50.851 & 852.000 \\
\hline GRAY,R.1987-2006 & 8 & 6.000 & 14.000 & 207.694 & 874.000 \\
\hline GROSSKOPF,S.1985-2007 & 0 & 0.000 & 0.000 & 0.000 & 5.625 .000 \\
\hline HAHN,T.2001-2007 & 16 & 29.000 & 2.000 & 217.384 & 938.000 \\
\hline HANDFIELD,RB.1995-2005 & 4 & 0.000 & 6.000 & 12.200 & 913.000 \\
\hline HART,SL. 1995-2005 & 7 & 11.000 & 7.000 & 219.983 & 831.000 \\
\hline HAWKEN,P.1993-2002 & 3 & 0.000 & 3.000 & 19.470 & 872.000 \\
\hline ISAKSSON,R.2000-2005 & 3 & 4.000 & 0.000 & 42.806 & 909.000 \\
\hline JAMES,P.1994-2001 & 2 & 0.000 & 2.000 & 0.000 & 903.000 \\
\hline JASCH,C.2001-2005 & 13 & 11.000 & 0.000 & 252.393 & 252.000 \\
\hline JONES,TM.1994-2002 & 4 & 0.000 & 5.000 & 87.699 & 881.000 \\
\hline KLASSEN,RD.1993-2008 & 13 & 21.000 & 7.000 & 252.393 & 852.000 \\
\hline KORHONEN,J.1999-2004 & 6 & 12.000 & 1.000 & 66.717 & 890.000 \\
\hline LABUSCHAGNE,C.2003-2006 & 12 & 21.000 & 6.000 & 189.550 & 839.000 \\
\hline LAVE,LB.1981-2002 & 1 & 1.000 & 0.000 & 0.000 & 962.000 \\
\hline LOVELL,CAK.1977-2000 & 0 & 0.000 & 0.000 & 0.000 & 5.625 .000 \\
\hline MCWILLIAMS,A.1997-2006 & 2 & 0.000 & 2.000 & 14.391 & 867.000 \\
\hline MELNYK,SA.1997-2003 & 4 & 0.000 & 4.000 & 12.200 & 913.000 \\
\hline PATTEN,DM.1990-2005 & 1 & 0.000 & 1.000 & 0.000 & 884.000 \\
\hline PEARCE,D.1988-1998 & 4 & 0.000 & 12.000 & 51.830 & 888.000 \\
\hline PERDAN,S.1998-2003 & 5 & 0.000 & 8.000 & 353.227 & 896.000 \\
\hline PORTER,ME.1979-2006 & 6 & 0.000 & 14.000 & 177.150 & 833.000 \\
\hline PRESTON,LE.1995-2002 & 0 & 0.000 & 0.000 & 0.000 & 5.625 .000 \\
\hline RENNINGS,K.1997-2007 & 1 & 0.000 & 5.000 & 0.000 & 884.000 \\
\hline RUSSO,MV.1997 & 1 & 0.000 & 2.000 & 0.000 & 884.000 \\
\hline SARKIS,J.1995-2007 & 7 & 9.000 & 8.000 & 13.700 & 910.000 \\
\hline SCHALTEGGER,S.1990-2005 & 4 & 0.000 & 12.000 & 0.000 & 862.000 \\
\hline SCHMIDHEINY,S.1992-2002 & 4 & 0.000 & 4.000 & 57.497 & 894.000 \\
\hline SHARMA,S.1998-2003 & 4 & 0.000 & 4.000 & 69.882 & 873.000 \\
\hline SHRIVASTAVA,P.1995-1996 & 0 & 0.000 & 0.000 & 0.000 & 5.625 .000 \\
\hline
\end{tabular}


Manfrin, P. M. et al. Um panorama da pesquisa em operações sustentáveis. Produção, v. 23, n. 4, p. 762-776, out./dez. 2013

Apêndice 1. continuação...

\begin{tabular}{cccccc}
\hline ID/Autores & $\begin{array}{c}\text { Grau de } \\
\text { centralidade }\end{array}$ & Grau de saida & $\begin{array}{c}\text { Grau de } \\
\text { entrada }\end{array}$ & Intermediação & Proximidade \\
\hline SIEGEL,D.1997-2006 & 2 & 0.000 & 4.000 & 14.391 & 867.000 \\
SMITH,AD.2004-2006 & 2 & 9.000 & 0.000 & 8.885 & 890.000 \\
SPENCE,LJ.1999-2006 & 3 & 4.000 & 0.000 & 71.667 & 901.000 \\
TYTECA,D.1996-2002 & 3 & 0.000 & 5.000 & 0.000 & 863.000 \\
VACHON,S.2001-2008 & 13 & 24.000 & 4.000 & 252.393 & 852.000 \\
VANDERLINDE,C.1995-2005 & 1 & 0.000 & 1.000 & 0.000 & 918.000 \\
VELEVA,V.1999-2003 & 6 & 1.000 & 12.000 & 43.205 & 845.000 \\
VREDENBURG,H.1998-2003 & 1 & 0.000 & 1.000 & 0.000 & 918.000 \\
WADDOCK,AS.1994-2004 & 3 & 0.000 & 3.000 & 50.851 & 852.000 \\
WAGNER,M.2000-2006 & 19 & 29.000 & 5.000 & 703.250 & 819.000 \\
WALTON,SV.1997-2005 & 4 & 0.000 & 6.000 & 12.200 & 913.000 \\
WASSENHOVE,VLN.1991-2006 & 0 & 0.000 & 0.000 & 0.000 & 5.625 .000 \\
WEHRMEYER,W.2001-2002 & 3 & 0.000 & 6.000 & 0.000 & 870.000 \\
WHYBARK,DC.1999-2009 & 2 & 0.000 & 4.000 & 0.000 & 916.000 \\
WICKS,AC.1999-2004 & 1 & 0.000 & 1.000 & 0.000 & 916.000 \\
WOOD,DJ.1991-1998 & 4 & 0.000 & 4.000 & 144.293 & 855.000 \\
ZADEK,S.1993-2004 & 3 & 0.000 & 3.000 & 20.429 & 872.000 \\
ZHU,Q.2001-2007 & 5 & 9.000 & 2.000 & 1.500 & 971.000 \\
İndice de centralização da rede (Entrada) & $3,424 \%$ & & & & \\
İndice de centralização da rede (Saída) & $1,644 \%$ & & & & \\
\hline
\end{tabular}

